\title{
ATRIBUTOS QUÍMICOS DO SOLO EM SISTEMA DE CACAU À PLENO SOL CONSORCIADO COM PLANTAS DE COBERTURA
}

\author{
AUTOR: RUAN JUNIOR BATISTA DE OLIVEIRA \\ CO-AUTOR/ORIENTADOR: JAQUELINE DALLA ROSA
}

\begin{abstract}
Resumo: A avaliação dos atributos químicos do solo é importante para qualquer cultivo, no caso desse estudo, em especial o cacau. A utilização de plantas de cobertura nas entrelinhas dos cacaueiros propõe uma melhoria na qualidade do solo e na ciclagem de nutrientes. $O$ objetivo deste trabalho foi avaliar os atributos químicos do solo em sistema de cacau à pleno sol e consorciado com plantas de cobertura. O delineamento experimental foi inteiramente casualizado com quatro tratamentos e quatro repetições. Os tratamentos referem-se a plantas de cobertura, implantadas nas entrelinhas do cacaueiro: i) Crotalária (Crotalária breviflora); ii) Braquiária (Braquiaria brizantha); iii) vegetação espontânea e iv) sem cobertura. Foram determinados o $\mathrm{pH}$ do solo em água, os macronutrientes ( $\mathrm{Ca} 2+, \mathrm{Mg} 2+, \mathrm{P}$ e $\mathrm{K}+$ ) e micronutrientes ( $\mathrm{Fe}, \mathrm{Zn}, \mathrm{Cu}, \mathrm{B}, \mathrm{Mn}$ ), parâmetros de fertilidade (Al3+, H+Al, SB, T, V, CTC). Foi determinada a produção de massa seca das plantas de cobertura, após estas atingirem o desenvolvimento pleno. A análise de solo demonstrou níveis nutricionais satisfatórios para o cultivo do cacaueiro. No primeiro ano implantação do experimento, a maior produção de massa seca foi obtida com cultivo de Crotalária breviflora, seguida de Braquiaria e vegetação espontânea. A massa seca produzida pelas plantas de cobertura é suficiente para proporcionar cobertura do solo nas entrelinhas do cacaueiro.
\end{abstract}

Palavras-chave: Fertilidade do solo, plantas de cobertura, cacau adensado. 